\title{
CRISES DE SENTIDOS: OS LIMITES DA UNIFICAÇÃO DAS OBRIGAÇÕES CIVIS E COMERCIAIS*
}

\author{
Luiz Aristeu dos Santos Filho ** \\ Matheus Pontelli Perobelli *** \\ Francini Feversani $* * * *$
}

\begin{abstract}
RESUMO: Vem-se discutido acerca da unificação das obrigações civis e comerciais, graças aos ditames implementados pelo Código Civil de 2002. Tal codex revogou os primeiros quatrocentos e cinqüenta e seis artigos do anacrônico Código Comercial de 1850. As mudanças atuais tornam os ramos do Direito algo confuso e trabalhoso, principalmente considerando a dificuldade de um convívio harmonioso, impedindo soluções que atendam as demandas dos envolvidos. A própria sociedade sofre quando uma questão que poderia ser resolvida com eficácia se perde em discussões acerca da aplicação de algo que é, antes de tudo, mera ficção corroborada. Visa-se discutir a tal unificação contrapondo a questão da unificação formal e a real, nos termos de uma tendência mundial da quebra dos antigos códigos generalistas e imprecisos em pequenas leis ou codificações especializadas e mais eficazes.
\end{abstract}

PALAVRAS-CHAVE: Direito Comercial. Atos de Comércio. Unificação. Obrigações.

ABSTRACT: In 2002 the Brazilian 1850 Commerce Law, based on the theory of the commerce act was replaced by the new codex of Civil Law. The original idea was a unification of commercial obligation and civil obligations. Otherwise the changes in terms of law are so fewer that the unification wasn't really happened. The purpose of this article is a discussion about this unification and its significations to the people and to the law in the country. This article has also as purpose the discussion about the purpose of a codex when most of countries all around the world adopted the notion of independent laws.

KEY-WORDS: Commerce law. Commerce transactions. Unification. Obligations.

*Trabalho de Pesquisa de Graduação do Centro Universitário Franciscano (UNIFRA).

**Acadêmico do Curso de Direito do Centro Universitário Franciscano (UNIFRA), Rio Grande do Sul, Brasil; Bacharel em Ciências Sociais e Administração, Mestrando em Integração Latino Americana da Universidade Federal de Santa Maria (UFSM), Rio Grande do Sul, Brasil. E-mail: luizaristeufilho@bol.com.br

***Acadêmico do Curso de Direito do Centro Universitário Franciscano (UNIFRA), Rio Grande do Sul, Brasil. E-mail: wolf_perobelli@hotmail.com. ***** Orientadora do Trabalho de Pesquisa e Professora do Curso de Direito do Centro Universitário Franciscano (UNIFRA), Rio Grande do Sul, Brasil. E-mail: francini@unifra.br 


\section{INTRODUÇÃO}

O mundo está em crise. Novas tecnologias alteram a vida dos seres humanos, exigindo celeridade. Tais mudanças afetam o Direito, uma ciência dinâmica. Mas tal dinâmica não é absoluta, principalmente no que se refere às obrigações civis: há determinados princípios que não admitem maior maleabilidade em sua aplicação. Outros institutos que são mutáveis, não admitindo sua "petrificação".

O presente artigo se dispõe a analisar o status do Direito Comercial em relação ao direito civil, observando os movimentos de unificação entre ambos. Estudar-se-á também a formação dos contratos civis e comerciais, tendo por norte as diferenças entre estes. Por último, tratar-se-á das obrigações civis e comercias, o que as difere e os motivos que levam parte da doutrina a afirmar que as obrigações estão unificadas.

Inicialmente será realizada uma discussão associada à utilização de definições arcaicas, advindas de diplomas seculares. Serão investigadas as alterações referentes ao Comercial/Empresarial brasileiro. O terceiro momento enfoca á questão das relações de consumo. Após estas, serão pontuadas as considerações finais do artigo.

\section{O DIREITO COMERCIAL OU EMPRESARIAL NO BRASIL}

Assim, serão apontadas questões acerca do diploma legal ora vigente, que rege as questões comerciais. Serão realizadas igualmente, observações concernentes aos limites teóricos e práticos do diploma legal anterior.

O Código Civil de 2002 trouxe modificações para a estrutura do direito comercial e das obrigações, no país. Esta promoveu a unificação teórica das obrigações ao alterar a perspectiva acerca da interpretação do direito comercial.

Cabe comentar que é intrínseco ao ser humano a satisfação de suas necessidades. Maslow, segundo Chiavenato (1994), formulou uma teoria comportamental que postula a busca pela satisfação das necessidades ocorre primeiro, acerca daquelas de nível mais inferior, tendencialmente em nível físico. Depois busca-se aquelas de nível intelectual.

Marx (2000) busca na história o fundamento das relações de poder. Pontua que a história é um complexo de lutas entre os elementos sociais. Não uma luta exclusiva pela satisfação suas necessidades, busca-se um controle dos meios de produção.

Seguindo tal tendência, porém focalizando elementos distintos, situa-se Schumpeter (1961). Em sua teoria, o universo de ação do indivíduo é a administração de vontades, sejam estas pessoais (individuais) ou coletivas É dentro de cada estrato social que atua a administração de vontades, visando o atingimento de objetivos 
Dentro de cada estrato as famílias se organizam em funções que definem o status. O status deve ser entendido no conjunto de interações sociais de uma determinada família, na sociedade. A luta (física ou teórica) pela conquista de funções importantes/essenciais é a constante nas suas atividades e na busca pelo poder.

Tal questão difere da teoria marxista, na qual o papel no estrato social é fixo. A administração dos conhecimentos dominados, a situação (econômica) familiar e suas alianças (casamentos) são os elementos com os quais se maximiza os ganhos de poder dentro da estrutura social, na teoria de Schumpeter.

Quem acrescenta tese mais controversa é Pareto (1984). Para este a realidade é igualmente um luta. Mas o que move o homem é o seu desejo incompleto pela satisfação, gerando-se a insatisfação. A insatisfação age no inconsciente determinando as necessidades a serem satisfeitas, sem que haja hierarquia lógica ou desestabilizando qualquer possibilidade de hierarquizá-las. Nessa "viagem de satisfação", o indivíduo explica seus atos de forma racionalmente válida para justificar sua ação.

Independentemente da teoria analítica das necessidades, o homem desenvolveu seu convívio com o objetivo de satisfazer suas necessidades. Qualquer ser humano busca o conforto e a possibilidade de alcançar dado bem com o menor esforço possível. Para tanto, desenvolveu a noção de troca e com ela a noção de comércio. A questão se complica não no que se refere às necessidades a serem satisfeitas, mas sim no que concerne aos atos que levarão até a essa satisfação.

O primeiro deles é a produção do bem. Desde os impensáveis insumos até o produto final, tudo precisa atender a lógica da cadeia produtiva e o consumidor-médio. Não seria estranho pensar que o homem deixaria de regrar as atividades que precedem a satisfação de suas necessidades, mesmo as mais supérfluas.

O Código Comercial, que regulamentava as atividades comerciais no país antes do Código Civil de 2002, foi criado em 1850, durante o reinado de Dom Pedro II. Ele dispunha a atividade comercial baseada na teoria dos "Atos de Comércio", utilizada na França, fundada nas aspirações da Revolução Francesa. A despeito das particularidades da classificação dos atos de comércio, falha em alguns casos, ela fundou o direito comercial brasileiro como baseado na atividade econômica visando o lucro, advinda da interposição habitual de troca, segundo Führer (2005).

Para Waldermar Ferreira, segundo Lippert (2003), 
(...) o ato de comércio distingue-se do ato jurídico de natureza civil pelo seu caráter especial, ou seja, pela mediação entre a produção e o consumo, 'no seu conceito profundo e eminentemente econômico' (LIPPERT, 2003, p. 52).

Configura-se ato de comércio aquele realizado 1) habitualmente por um indivíduo (profissional) e 2) com intenção da obtenção de resultado financeiro positivo.

Lippert (2003) aponta que de tal definição, passou-se à necessidade de estruturar atos considerados como de comércio. A primeira tipologia visava determinar aqueles atos mercantis, de modo exemplificativo. A segunda buscava enumerar os elementos caracterizadores dos atos de comércio, com teor legal-burocrático.

Nota-se que mesmo antes da implementação do Código Civil de 2002 havia semelhança entre os atos de comércio e jurídicos. Isso se deve ao fato de que o ambos tem os mesmos requisitos essenciais: 1) a capacidade dos agentes; 2) a licitude do objeto e 3) formalidades do ato, para aqueles nos quais a formalidade é da sua essência.

É interessante notar que tal questão é controversa, pois

(...) compreendeu-se que o negócio jurídico é tão-somente uma oportunidade para a manifestação da autonomia privada (entendida esta como o poder de dispor a respeito de seus interesses nas relações com os outros). A autonomia privada fornece o suporte de fato sobre o qual incidirão as normas jurídicas, atribuindo-lhes os efeitos que lhes são próprios, não mais de acordo com a vontade, mas de acordo com os fins a que se propõe a ordem estatal. (PERIN JUNIOR, 2000)

E nisso, não há diferença em relação ao negócio jurídico e o ato de comércio. Diferir-se-iam apenas pela "ligação produção-consumo" do ato de comércio.

Pode-se notar que tal definição "genérica" pautada em um conceito abrangente é um complicador. Principalmente pelas influências das atividades econômicas não apenas na produção de riquezas, mas sobremaneira possibilitadora do desenvolvimento da nação e da sua indústria. A questão é mais delicada, pois mesmo se baseando na teoria dos atos de comércio, o Código Comercial não o definiu.

Coube ao Regulamento 737, de 1850 tal determinação legal enumerativa, valendo-se de seu art. 19. O paradoxo está no fato de que o Código Comercial ao adotar a teoria dos atos de comércio, generaliza-os. Já o Regulamento 737 ao utilizar uma definição enumerativa estipula um rol estrito de atos considerados como de comércio.

Tal questão foi resolvida pelo Código Civil de 2002 que para Schuch (2005) (...) estabeleceu o delineamento e a normatização do Direito de Empresa, abrangendo a disciplina legal relativa à atividade empresarial e às sociedades. Trata-se, sem sombra de dúvidas, da unificação codificada do Direito das 
Obrigações, incluindo em seu âmbito o que se classifica comumente como obrigações civis e comerciais. A unificação das obrigações pressupõe, necessariamente, o trato conjunto dos agentes profissionais que as desenvolvem. Assim, com base num conceito comum às atividades civis e comerciais, qual seja, o de atividade econômica, superou-se a dicotomia sob a figura da empresa e do empresário, regulando-se a 'Atividade Negocial' em si. (SCHUCH, 2005)

Feitas estas considerações, é necessário especificar o caráter das modificações propostas pelo Código Civil de 2002. Tal questão será o foco do próximo item.

\section{O ESCOPO DAS ALTERAÇÕES}

No presente item se inicia a apresentação das questões que se modificaram pelo Código Civil de 2002. Seguindo-se a esta, serão apresentados os elementos relevantes não abarcados pelo diploma legal ascendente.

\section{1 - Obrigações Civis e Comerciais}

O Código Comercial vigente no Brasil até 2002, era "filho" de sua época. Como tal, padecia dos problemas e benesses a ela inerentes. Não poderia tal diploma, sem revisão, abarcar os elementos que passaram a figurar em termos econômicos no mundo.

Reale (2003), acerca da utilidade do Código Comercial brasileiro, pontua que

A indústria e o poderoso ramo dos serviços tornaram indispensável levar em consideração o conceito de empresa, para estabelecer a unidade das obrigações civis e comerciais que já se tornara uma realidade no Brasil em virtude do obsoletismo do Código Comercial de 1850. Os juristas não faziam mais referência ao Código de 1850 mas em matéria de Direito Obrigacional tinham presente especificamente o Código Civil. (REALE, 2003)

A inovação implementada pelo Código Civil de 2002 foi a mudança de foco da determinação da atividade comercial. Isso ocorre, pois em seu art. 996 considera “(...) empresário quem exerce profissionalmente atividade econômica organizada para a produção ou a circulação de bens ou de serviços" (BRASIL, 2006, p. 351).

Mas ao mesmo tempo nota-se a posição tomada por Cottcky, para quem

Do ponto de vista jurídico, comerciante passou a ser gênero, com muitas espécies. O direito econômico não reconhece a diferença entre a produção agrária e a de outros setores. Defende a idéia de que o comerciante está num conceito adequado à realidade econômica e que o comerciante é apenas um setor do empresariado, da mesma forma que existem outros setores. (COTTCKY apud PIMENTEL, 2000). 
A postura adotada pelo Código Civil de 2002, definindo o conceito de empresário supera alguns dos problemas existentes. Graças a tal percepção,

(...) o comércio passou a representar apenas uma das várias atividades reguladas por um Direito mais amplo, o Direito Empresarial, que abrange o exercício profissional de atividade econômica organizada para a produção ou a circulação de bens ou serviços. (FUHRER, 2005, p. 17)

Mais do que mera alteração formal, pontua Souza (2006) que a questão de modelo atitudinal foi alterada, pois

De um modelo individualista, solidamente alicerçado nos velhos dogmas do Estado Liberal, que transformava os princípios da autonomia da vontade e da imutabilidade dos contratos em valores quase absolutos, passamos agora para um sistema profundamente comprometido com a função social do direito, e preocupado com a construção da dignidade do homem e de uma sociedade mais justa e igualitária. (Souza, 2006)

Tal posicionamento protege abusos na estipulação de cláusulas contratuais. A Lei 8.078/90, o chamado "Código de Defesa do Consumidor", se encontra recepcionado pelo novo diploma. Corrobora-se assim, uma visão protecionista do elo mais fraco da cadeia de consumo, baseada na teoria do risco, no que se refere à responsabilidade civil.

Foi relevantíssima a implementação da teoria da boa-fé objetiva, em substituição à boa-fé subjetiva. Ela ressaltou mais do que um comportamento meramente ético nas relações contratuais: priorizou-o. Viabilizou o estabelecimento de relações que, se não são igualitárias no momento, entre as partes, pelo menos caminham em tal direção.

Passou-se de uma postura de mera aceitação da intenção das partes, visto que Os belos ideais da Revolução Francesa, principalmente a igualdade e a fraternidade, foram incorporados ao discurso jurídico e fundamentaram dois importantíssimos princípios da teoria clássica dos contratos: a igualdade formal das partes contratantes e a liberdade de contratar (incluindo aí a liberdade contratual) (BORGES, 2005).

Porém a estruturação dos mercados e percepção liberal evoluíram. Saiu-se de uma posição confortável, em uma Europa liberal, postada no esforço do welfare state (estado do bem-estar social) e da igualdade formal, segundo Giddens (1999), para uma fase de reconhecimento de diferenças. Uma realidade alimentada, retro-alimentada e calcada no paradigma social-democrata, inspirando-se nas idéias mais puras (e apontadas, por alguns autores, como ingênuas e hedonistas) de John Stuart Mill.

Passou-se sim ao império do convívio harmonioso. O objetivo maior do contrato é a preservação dos interesses coletivos, seja pelas imposições limitantes dos elementos 
estatais, seja pelo advento da função social do contrato, cláusula já prevista constitucionalmente e que teve seu escopo reforçado pelo Código Civil.

O Código Civil de 2002 resolveu também a definição das empresas prestadoras de serviço, pois desde antigamente,

As sociedades prestadoras de serviços apresentam características que as podem mostrar aparentemente como sociedades civis, o que não é absolutamente verdadeiro e pode levar a conclusões equivocadas.

É generalizada em diversos meios a idéia de que a prestação de serviços corresponde invariavelmente ao campo do Direito Civil. Nada mais errado, pois, já que desde épocas remotas, algumas atividades dessa natureza foram consideradas mercantis, como é o caso das empresas de transporte, que desde o Regulamento $\mathrm{n}^{\circ} 737$, de 1850 , passando pelo Código Comercial, são consideradas empresas comerciais. (PIMENTEL, 2000)

Ao expandir as possibilidades e definir conceitos dúbios do Código Comercial, permitiu-se a expansão do âmbito de suas proposições. Ao deixar de lado a teoria dos atos de comércio e adotar a teoria da empresa, o Código Civil permitiu ao Direito Comercial sua evolução ao direito Empresarial, de escopo muito maior e abrangente.

Tal posição, porém não é segura, pois em alguns elementos, não houve modificações reais, sendo implementadas pela mudança. O que houve foram apenas “atualizações” e não de todo felizes. Tal questão será explorada no próximo item.

\section{2 - Questões Controversas na Unificação: Unificação Real X Formal}

Pelo exposto anteriormente a implementação do Código Civil de 2002 auxiliou na superação de alguns problemas referentes ao Direito Comercial brasileiro. Tal tese é defendida pelo fato de que a nova codificação uniu elementos das obrigações civis e comerciais. No entanto, tal percepção não é necessariamente de todo feliz.

A principal questão à defesa da infelicidade do Código Civil de 2002 é justamente a unificação. O Direito Comercial enquanto codificação diversa moveu-se nos últimos 100 anos em sentido próprio, nem sempre igual ao do direito obrigacional civil. A união representaria algo necessário.

De início, cabe apontar uma tendência mundial da busca por uma especialização dos códigos. Nota-se a existência em países como a Itália ou a Alemanha, que tanto influenciaram as codificações adotadas no Brasil, diplomas especializados de direito.

Miguel Reale, falando do Código Civil

(...) que não iríamos substituir afoitamente o Código Civil de 1916, que vigorou 85 anos. Esse Código, apesar de ter sido superado em vários pontos, quer em 
razão do progresso social, quer em razão do advento de novas formas de tecnologia e de visão científica do Direito, é das mais altas realizações do pensamento jurídico universal. (REALE, 2003)

Será o objetivo de "preservar o mais que fosse possível o Código anterior, sem pensar numa substituição abrupta e uma ruptura sem sentido.” (REALE, 2003) não foi algo pensado para o Código Comercial? Conta Reale que chegou a ser montada uma comissão destinada a avaliar a questão do Direito das Obrigações,

Mas esse plano não logrou êxito porquanto houve uma reação na elite jurídica nacional contra a idéia de qualquer desmembramento da legislação civil. (...) Esta tomada de posição não correspondia às aspirações jurídicas nacionais, razão pela qual não teve êxito. (REALE, 2003)

Apenas "maquiou-se" as transformações jurisprudenciais das décadas passadas e que figuravam entre os modos de leitura da realidade. $\mathrm{O}$ mesmo acontecendo com a parte relativa ao Código Comercial, ora incorporado. Veja-se, por exemplo, que foi feliz o Código Civil de 2002 ao estabelecer o conceito de empresário. Para Nerilo (2002), a

(...) palavra empresa tem o significado de empreendimento, aquilo que se empreende; Porém, para a economia essa palavra assume uma conceituação mais complexa, designando a organização econômica destinada a produção ou venda de mercadorias ou serviços, tendo em geral como objetivo o lucro. (NERILO, 2002)

Exime-se a mesma codificação em classificar ou denominar o que é uma empresa. Além disso, boa parte da dita "unificação", salvo aqueles elementos já comentados nas páginas anteriores, é apenas, nas palavras de Perin Junior, a

(...) justaposição formal da matéria civil ao lado da matéria comercial, regulada num mesmo diploma. Ratifica-se que se constitui em simples unificação formal. Isso, na verdade, nada diz de científico e de lógico, pois como se disse anteriormente, o Direito Comercial, como disciplina autônoma, não desaparecerá com a codificação, pois nela apenas se integra formalmente. (PERIN JUNIOR, 2000)

Corrobora a posição da "união artificial" a opinião de Requião, para o qual "o artificialismo do critério de unificação formal adotado, criou no Projeto a preocupação de prescrever o adjetivo "comercial" ou "mercantil". Essas expressões são tabus..." (REQUIÃO apud PERIN JUNIOR, 2000).

Apesar da união física das duas matérias no mesmo código, estas permanecem separadas. Elas pertencem a livros distintos, postados para efeitos formais dentro do 
mesmo código. Trata-se de uma conveniente unificação que não visa reconstituir as matérias de modo teórico, visa apenas colocá-las juntas no mesmo lugar.

O ideal seria a postura refutada por Reale, na qual se limitaria o Código Civil à sua Parte Geral. Para observar adequadas mudanças deve-se observar o mundo atual.

O que se faz necessário contestar, entretanto, é que se assim foi outrora, os tempos modernos não só ditam como impõe a fragmentação legislativa. A codificação foi um ideal de síntese, bem própria do idealismo do século passado, compatível com uma sociedade aparentemente estática e imóvel, de que foi Stuart Mill um dos mais convencidos enunciadores. (PERIN JUNIOR, 2000)

O mundo em constante alteração não admite mais codificações gerais. É necessário um elemento legal que permita movimentos e alterações sociais hoje comuns, como a internet, o direito internacional, etc, que atingem nossas instituições jurídicas todos os dias, confrontando a letra posta da regra com uma realidade mutante.

Se o Brasil deve seguir, como exposto por Reale, "estabilizando suas relações", pela mera "adaptação" das regras antigas, afastar-se-á não só de seus parceiros comerciais. Afastar-se-á da necessidade primordial do direito, que é regular a vida em sociedade, oferecendo regras capazes de dirimir conflitos em seu cerne.

França, Itália, Alemanha e até mesmo a Argentina passaram por grandes transformações legais. As respostas, conforme idealizadas por estes países não passaram pelo simples "remendar" de regras. Passou pelo estudo sério e compromissado com a eficácia e com a efetividade das regras, de forma a delimitar um direito aplicável às relações que este deseja regular e que a sociedade anseia por ver resolvidas.

Feitas as devidas considerações sobre as alterações dentro do nosso ordenamento jurídico. Passa-se agora a tecer determinados comentário sobre a questão da responsabilidade, no código civil sob uma visão das relações de consumo. Tal questão será observada no próximo item.

\section{3. - Responsabilidade Comercial e Relação de Consumo}

Como incitado no item anterior, para melhor compreensão da não incorporação das obrigações comercias pelo direito civil, se faz necessária a análise da responsabilidade e as relações de consumo. É clarividente que ao se falar de responsabilidade comercial, não se pode deixar de lado as relações de consumo e o Código de Defesa do Consumidor. Porém, é importante que seja traçada uma linha de 
pensamento que permita a análise das relações de consumo e a responsabilidades dos comerciantes nas suas relações.

Ainda, se faz pertinente um breve relato sobre a responsabilidade civil dentro do ordenamento jurídico pátrio. Portanto passa-se à devida analise.

\subsubsection{Responsabilidade Civil}

É matéria indiscutível que a teoria da responsabilidade civil integre a ceara do direito das obrigações. Em defesa desta usam-se os dizeres de Carlos Roberto Gonçalves, que afirma:

A teoria da responsabilidade civil integra o direito obrigacional, pois é a principal conseqüência da prática de um ato ilícito é a obrigação que acarreta, para o autor (...) (GONÇALVES, 2002: Pág. 1)

O ato ilícito gerará no mundo jurídico uma obrigação, ou seja, é fonte desta. Este ato lícito pode ser fruto de uma omissão culposa ou dolosa, dependendo de sua espécie. Sempre deverá ser praticada por pessoa imputável, violando o direito alheio ou causando dano (prejuízo) a outrem.

$\mathrm{O}$ ato ilícito pode vir a violar uma norma de direito presente a toda sociedade, ou a uma norma posta entre partes. Dessa forma, a responsabilidade pode ser contratual (entre as partes) ou ainda extracontratual (violação de direito codificado), esta ultima também conhecida como responsabilidade aquiliana.

A idéia de responsabilidade tradicionalmente se firma na ocorrência de culpa. Culpa, essa, lato sensu, sendo que engloba o dolo, ou seja, a vontade de fazer o ato, e a culpa stricto sensu, que é a falta de prudência, perícia e zelo, sempre levando em consideração a atuação do homem médio, presente na sociedade.

Dentre as várias classificações da responsabilidade civil, há uma que se destaca, tanto, no direito civil, como no, direito comercial. A responsabilidade contratual e extracontratual se faz muito presente na prática comercial e também na vida civil.

Da mesma forma, é importante ter-se em mente a forma como é tratada a responsabilidade obrigacional dentro das relações de consumo, tendo em vista que as relações de comerciais envolvem relações de consumo. Portanto far-se-á uma análise desta responsabilidade.

\subsubsection{Responsabilidade no CDC}


É clarividente o fato de que ocorre certo distanciamento entre a responsabilidade do Código Civil e o CDC. O primeiro trata de forma de respostas contra atos ilícitos praticados, dentro de um contrato ou não, onde os contraentes estão um perante o outro de forma eqüitativa. Não há um grande desnível entre as partes.

Por outro lado, o CDC trata de relações que, em tese, entendem-se desproporcionais. Ou seja, a função do CDC é proteger a parte mais fraca da relação de consumo, do comércio em geral, neste ponto tem-se a responsabilidade do comerciante perante o seu cliente. É exigido pelo código, que o comerciante respeite a vulnerabilidade daquele que procura como ele transacionar.

É intensa a discussão na doutrina e na jurisprudência sobre a aplicação da proteção do CDC às pessoas jurídicas. É interessante notar que a doutrina está formando uma teoria que, utilizando-se de princípios hermenêuticos, estabelece um padrão de análise que não agrida àqueles que o código prima à defesa (consumidoras finais). Porém, a jurisprudência já decidiu que é incabível o uso do CDC para proteger pessoa jurídica contra pessoa jurídica, apenas quando não sejam consumidoras finais. Estes casos, por serem contratos usuais, ou seja, não trazerem uma disparidade entre seus contratantes, ainda ficam sob os auspícios do Código Civil.

De diferente modo age esta, em relação à responsabilidade presente no $\mathrm{CDC}$, que rege a relação do comerciante perante o consumidor. Esta responsabilidade considera o fato do consumidor ser a parte mais fraca, em tese, de uma relação de consumo. Segundo Gonçalves essa responsabilidade é objetiva.

O diploma consumerista consagrou a responsabilidade objetiva do fornecedor, tendo em vista especialmente o fato de vivermos, hoje, em uma sociedade de produção e de consumo em massa, responsável pela despersonalização ou desindividualização das relações entre produtores, comerciantes e prestadores de serviços, em um pólo, e compradores e usuários do serviço, em outro. (GONCALVES, 2002: 153)

Essa responsabilidade que protege o consumidor é exigida de forma subsidiária daqueles que tiveram participação sobre o produto. Ou seja, todos aqueles mencionados na citação acima, são coobrigados solidariamente, se o produto contiver um vício, este deverá ser sanado por qualquer um dos participantes da cadeia de consumo.

Dessa forma vê-se que a responsabilidade obrigacional na cadeia de consumo não é a mesma surgida dos contratos ou dos ilícitos civis. Esta prima pela proteção da relação como um todo, tendo a preocupação em sanar o ilícito praticado. Aquela prima pela proteção da parte hipossuficiente da relação. 


\section{CONSIDERAÇÕES FINAIS}

No decorrer do presente artigo foram apresentado, primeiramente, considerações em relação a história do direito comercial no Brasil e suas influencias externas. Da mesma forma foi apresentada a forma como foi obtida a mudança de teoria dentro Direito Comercial, com a entrada em vigor do novo Código Civil. Fez-se uma análise em torno da teoria dos atos de comércio e o seu uso até anos atrás pelo, em parte, revogado Código Comercial.

Ainda sobre a teoria dos atos de comércio, viu-se que a diferenciação básica desta para os atos civis se da apenas no fato da relação acontecer entre os comerciantes. Também foi levemente tratada a mudança do Código Civil, que optou pela adoção d teoria da empresa, sendo esta uma teoria mais moderna e adaptada aos tempos atuais. Simultaneamente, apresentou-se a justificativa dos atos de comércio e sua ineficiência nos dias modernos, devido às novas formas de fabrico do produto e todo o envolto em torno do produto em seu comércio.

Em um segundo momento foi tratado sobre o escopo das alterações. No primeiro tópico relativo às obrigações civis e comerciais fala mais profundamente sobre as mudanças em relação às teorias reafirmando que o Código Civil de 2002, ao definir o que constitui o empresário supera alguns dos problemas existentes anteriormente.

Falou-se também na relevantíssima implementação da teoria da boa-fé objetiva, em substituição à boa-fé subjetiva. E ainda que ela ressaltou mais do que um comportamento meramente ético nas relações contratuais: priorizou-o, no âmbito da relação.

Assim passou-se para a analise da unificação das obrigações civis e comerciais. Onde simples fato de a nova codificação representar a revolução de unir elementos do direito referente às obrigações civis e aquelas advindas de relações comerciais, o que não foi feliz pelo sentido de apenas formar na legislação algo que já ocorria na prática.

Neste ponto começa a ser delineada as idéias principais do artigo. Vê-se, nele que o Código Civil buscou manter a estruturação presente no anterior, apenas "maquiando" as transformações jurisprudenciais que surgiram desde décadas passadas e que figuravam entre os modos de leitura da realidade. $\mathrm{O}$ mesmo acontecendo com a parte relativa ao Código Comercial, ora incorporado.

Ainda tem-se uma breve análise de como a obrigacional comercial se relaciona com o direito do consumidor e o que isso interfere dentro da sistemática obrigacional. 
Explicitou-se a não influencia do direito do consumidor dentro da possível união das matérias de direito privado. E por fim fez-se uma breve análise das teorias atinentes ao conceito de consumidor.

Concluindo sobre o assunto, entende-se que, apesar da existência de uma união em termos de comporem ou ocuparem as duas matérias o mesmo código, permanecem, ainda, estas separadas. Isso ocorre, pois pertencem a livros distintos, apenas colocados para efeitos formais dentro do mesmo código.

Trata-se, portanto de uma conveniente unificação que não tem por escopo unificar as matérias propriamente ditas, em seu modo teórico, tão-somente visa colocalas juntas no mesmo lugar. Ainda que fosse possível a unificação das obrigações civis e comerciais o conturbado mundo em constante alteração no qual vivemos não admite mais codificações gerais, principalmente nos termos em que fora implementada.

\section{REFERÊNCIAS BIBLIOGRÁFICAS}

BRASIL. Código civil; código comercial; código de processo civil; constituição federal 2. ed. São Paulo: Saraiva, 2006.

BORGES, Roxana Cardoso Brasileiro. A atual teoria geral dos contratos. Jus Navigandi, Teresina, a. 9, n. 811, 22 set. 2005. Disponível em: <http://jus2.uol.com.br/ doutrina/texto.asp? id=7267>. Acesso em: 10 abr. 2006.

CHIAVENATO, Adalberto. Administração: teoria, processo e prática. São Paulo: Makron Books, 1994.

FÜHRER, Maximilianus Cláudio Américo. Resumo de direito comercial (empresarial). São Paulo: Malheiros, 2005.

GIDDENS, Anthony. Para além da esquerda e da direita. São Paulo: UNESP, 1999.

GONÇALVES, Carlos Roberto. Comentários ao Código Civil. São Paulo: Saraiva, 2002

LIPPERT, Márcia Mallmann. A empresa no código civil: elemento de unificação no direito privado. São Paulo: Revista dos Tribunais, 2003.

MARX. Coleção os pensadores. São Paulo: Nova Cultural, 2000.

NERILO, Lucíola Fabrete Lopes. O direito empresarial superando o arcaico sistema dos atos de comércio. Jus Navigandi, Teresina, a. 6, n. 54, fev. 2002. Disponível em: <http://jus2.uol.com.br/doutrina/texto.asp?id=2698>. Acesso em: 25 mai. 2006.

PARETO, Vilfredo. Sociologia. São Paulo: Ática, 1984.

PERIN JUNIOR, Ecio. A teoria da vontade na formação dos contratos e a autonomia do direito comercial em relação ao direito civil face ao projeto do novo código civil. Jus Navigandi, Teresina, a. 4, n. 45, set. 2000. Disponível em: <http://jus2.uol.com.br/doutr ina/texto.asp?id=518>. Acesso em: 14 jun. 2006.

PIMENTEL, Dolimar Toledo. A obrigatoriedade das empresas prestadoras de serviço contribuírem para o sesc e o senac. Jus Navigandi, Teresina, a. 4, n. 42, jun. 2000. Disponível em: <http://jus2.uol.com.br/doutrina/texto.asp?id=1422>. Acesso em: 06 mar. 2006. 
REALE, Miguel. O processo da reforma do código civil. Disponível em <http://www. tcm.sp.gov.br/legislacao/doutrina/07a11_04_03/1miguel_reale1.htm>. Acesso em: 06 jun. 2006.

SCHUMPETER, J. Imperialismo e classes sociais. Rio de Janeiro: Zahar, 1961.

SOUZA, Sylvio Capanema de. O novo código civil e a reformulação da teoria das obrigações e dos contratos. Disponível: <http://www.uj.com.br/publicacoes/doutrinas/ defaultasp?action=tema\&idtema=3>. Acesso em: 29 abr. 2006. 